\title{
Capsule Endoscopy in the Small Bowel Crohn's Disease
}

\author{
Federico Argüelles-Arias, Juan Rodríguez-Oballe, \\ Calixto Duarte-Chang, Luisa Castro-Laria, Josefa María García-Montes, \\ Ángel Caunedo-Álvarez, and Juan Manuel Herrerías-Gutiérrez
}

\author{
Clinical Unit of Gastroenterology, University Hospital Virgen Macarena, Seville, Spain \\ Correspondence should be addressed to Federico Argüelles-Arias; farguelles@telefonica.net
}

Received 24 November 2013; Revised 28 January 2014; Accepted 29 January 2014; Published 11 March 2014

Academic Editor: R. Eliakim

Copyright (C) 2014 Federico Argüelles-Arias et al. This is an open access article distributed under the Creative Commons Attribution License, which permits unrestricted use, distribution, and reproduction in any medium, provided the original work is properly cited.

\begin{abstract}
$\mathrm{CD}$ is a chronic inflammatory disorder associated to mucosal and transmural inflammation of the bowel wall. It is well known that CD can affect the entire gastrointestinal. Therefore, ileocolonoscopy and biopsies of the terminal ileum as well as of each colonic segment to look for microscopic evidence of $\mathrm{CD}$ are the first-line procedures to establish the diagnosis. However, it has been observed that up to $30 \%$ of the patients have only small bowel involvement. Evaluation of the small bowel has been made with radiological procedures, barium radiography, and abdominal computed tomography or by ileocolonoscopy or enteroscopy, but they have many recognized limitations. CE is undoubtedly a very useful diagnostic tool proposed to observe small-bowel lesions undetectable by conventional endoscopy or radiologic studies. We review different studies that have been published reporting the use of $\mathrm{CE}$ in suspected and evaluation of the extension or the recurrence in $\mathrm{CD}$ and also its use in pediatric population and its complications.
\end{abstract}

\section{Introduction}

The incidence and prevalence of Inflammatory Bowel Disease (IBD) have increased in the past 50 years, specifically up to 6-15/100,000 and 50-200/100,000 persons, respectively, for Crohn's disease (CD) in the western countries [1]. These patients may have unexplained fever, weight loss, anaemia, pain, or diarrhea, but depending on the digestive segment affected the symptoms will be different. Although there is no gold standard test for the diagnosis of small bowel $\mathrm{CD}$ [2], diagnosis should be made using a combination of clinical, endoscopic, radiological, histology, and biochemical tests.

$\mathrm{CD}$ is a chronic inflammatory disorder associated with mucosal and transmural inflammation of the bowel wall. It is well known that CD can affect the entire gastrointestinal tract from the mouth to the anus although the most common presentation is ileum-colon, $50 \%$ of the cases [1]. Therefore, ileocolonoscopy and biopsies of the terminal ileum as well as of each colonic segment to look for microscopic evidence of $\mathrm{CD}$ are the first-line procedures to establish the diagnosis [3].
However, it has been observed that up to $30 \%$ of the patients have only small bowel involvement $[4,5]$. Jejunal lesions are also detected in more than half of the patients with $\mathrm{CD}$ and the prevalence of jejunal lesions is higher when the terminal ileum is involved [6]. It is well known that the presence of jejunal lesions is associated with an increased risk of further clinical relapse [7] and therefore an early and rapid diagnosis is necessary.

Evaluation of the small bowel has been made with radiological procedures, barium radiography, and abdominal computed tomography (CT) or by ileocolonoscopy or enteroscopy, but they have many recognized limitations. In this context, Magnetic Resonance Enterography (MRE) has emerged as a modern technique with increasing implantation and is recognized as a useful and effective tool for the diagnosis of intestinal injury. However, it is not efficient to display subtle or mucosal lesions and versus the capsule endoscopy (CE) it has shown lower sensitivity for the diagnosis of small bowel CD [8]. One study [9] compared CE with MRE in patients with suspected small bowel disease. CE depicted a higher number of inflammatory lesions in the jejunum and 
TABLE 1: Comparative yield of CE and cross-sectional imaging (CSI) in patients with suspected CD (modified from Doherty et al. [58]).

\begin{tabular}{|c|c|c|c|c|}
\hline Study & CSI technique & Patients & Yield of CE & Yield of CSI \\
\hline Voderholzer et al. [59] & CT enteroclysis & $N=41$ & $61 \%$ & $29 \%$ \\
\hline Eliakim et al. [16] & CT enteroclysis & $N=35$ & $77 \%$ & $50 \%$ \\
\hline Hara et al. [60] & CT enteroclysis & $N=17$ & $71 \%$ & $53 \%$ \\
\hline Jensen et al. [21] & $\begin{array}{c}\text { CT enteroclysis } \\
\text { MRE }\end{array}$ & $N=93$ & $\begin{array}{c}30 \% \\
\text { Sens.: } 100 \% \\
\text { Spec.: } 91 \%\end{array}$ & $\begin{array}{c}\text { CTE: } \mathbf{3 3 \%} \\
\text { Sens.: } 76 \% \\
\text { Spec.: } 85 \% \\
\text { MRE: } \mathbf{2 8 \%} \\
\text { Sens.: } 81 \% \\
\text { Spec.: } 86 \%\end{array}$ \\
\hline Casciani et al. [61] & MRE & $N=60$ & $\begin{array}{l}\text { Sens: } 90,9 \% \\
\text { Spec: } 92,3 \%\end{array}$ & $\begin{array}{l}\text { Sens.: } 100 \% \\
\text { Spec.: } 97,6 \% \\
\end{array}$ \\
\hline Tillack et al. [62] & MRE & $N=19$ & $95 \%$ & $95 \%$ \\
\hline Albert et al. [63] & MRE & $N=52$ & $\begin{array}{c}93 \% \\
\text { Sens.: } 92 \% \\
\text { Spec: } 100 \%\end{array}$ & $\begin{array}{c}88 \% \\
\text { Sens.: } 77 \% \\
\text { Spec: } 80 \%\end{array}$ \\
\hline
\end{tabular}

proximal ileum compared with MRE. CE is undoubtedly a very useful diagnostic tool proposed to observe small bowel lesions undetectable by conventional endoscopy or radiologic studies.

\section{Capsule Endoscopy in Suspected and Established Crohn's Disease}

Many studies have reported the use of CE in suspected CD with previous negative ileocolonoscopy. Herrerías et al. [10] studied 21 patients who underwent CE because of abdominal pain, diarrhea, weight loss, fever, anemia, and elevated Creactive protein. Colonoscopy and small bowel series were negative in all patients. In nine patients (43\%) the CE found lesions compatible with CD. Fireman et al. [11] also reported a $71 \%$ yield, in which 12 of 17 patients with normal small bowel series and colonoscopy, but with a high clinical suspicion of having $\mathrm{CD}$, were found to have lesions compatible with this condition: aphthae, linear or irregular ulcers, and mucosal fissures. In other studies, the CE diagnosed Crohn's disease in $26 \%$ [12], 59\% [13], or 52,4\% [14] of the patients. As we can see, results are heterogeneous and depend on study definitions, design, and follow-up.

The improvement of CE for the study of small bowel has happened because of the inconsistent results of the radiological studies. Small Bowel Follow-Through (SBFT) and Enteroclysis are limited by poor sensitivity for early or subtle inflammatory lesions of $\mathrm{CD}$ and for ionizing radiation exposure; many studies have shown better yield for CE [15-20]. Cross-sectional imaging techniques such as CT Enterography (CTE) and Magnetic Resonance Enterography (MRE) have replaced the traditional techniques with better results (see Table 1). The largest comparative study of multiple small bowel imaging modalities involved a comparison of CE, CTE, and MRE performed after ileocolonoscopy [21]. The results reported a significantly superior detection of $\mathrm{CD}$ in the proximal small bowel by CE compared with both CTE and MRE. In suspected or newly diagnosed CD, MRE and
CTE have comparable sensitivities and specificities and, in patients without endoscopic or clinical suspicion of stenosis, CE should be the first-line modality for detection of small bowel Crohn's disease beyond the reach of the colonoscope. Overall, these comparative studies suggest that $\mathrm{CE}$ is more sensitive than SBFT and may be more sensitive than crosssectional imaging.

Subsequently, two meta-analyses that study the efficacy of the CE have been published. Triester et al. [22] published the first one, including nine studies with 250 patients comparing CE with other imaging techniques of the small bowel, concluding that $\mathrm{CE}$ is superior to all other modalities for diagnosing nonstricturing small bowel $\mathrm{CD}$, with a number needed to test (NNT) of 3 to yield one additional diagnosis of CD over small bowel barium radiography and NNT $=7$ over colonoscopy with ileoscopy. The other one has recently been published [23] and a total of 12 trials were compared. Eight trials $(n=236)$ compared CE with colonoscopy plus ileoscopy, four trials $(n=119)$ compared CE with Computerized Tomography Enteroclysis (CTE), two trials ( $n=102$ ) compared CE with Push enteroscopy, and four trials $(n=123)$ compared CE with MRE. Again this metaanalysis has demonstrated that CE is superior to small bowel radiography, CTE, and colonoscopy plus ileoscopy in the evaluation of suspected CD patients.

Furthermore, the yield of the CE has been compared with push enteroscopy and double-balloon enteroscopy (DBE). CE has a higher yield than push enteroscopy [20] and recently two meta-analyses have been published, concluding that $\mathrm{CE}$ and DBE have comparable diagnostic yield in small bowel diseases [24, 25]. Consequently, CE should be the initial diagnostic test and, because of its therapeutic capabilities, DBE may be indicated in patients with a positive finding on $\mathrm{CE}$ requiring a biopsy or therapeutic intervention.

Also, in order to determine patient burden and patient preference for MRE, CE, and balloon-assisted enteroscopy in patients with suspected or known CD or occult gastrointestinal bleeding, a study was developed and CE was preferred 


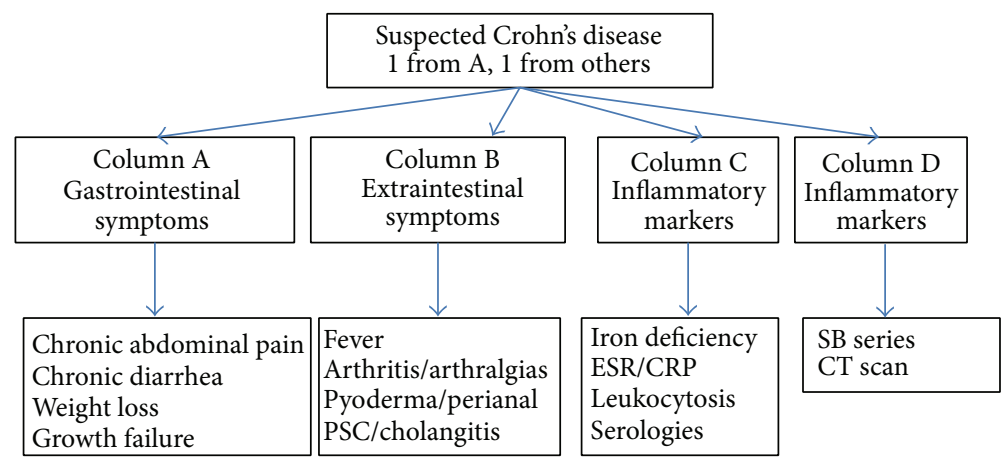

FIGURE 1: Criteria for suspected Crohn's disease [30]. PSC: primary sclerosing cholangitis; ESR: erythrocyte sedimentation rate; CRP: Creactive protein; SB series: small bowel series; CT scan: computed tomography scan.

to MRE and balloon-assisted enteroscopy and it also had the lowest burden [26].

It is important to take into account that many lesions described in studies of suspected CD are not specific and this could explain the variability of the "diagnostic yield" of CE. Also, it must be considered that the "diagnostic yield" is different to either "sensitivity" or "specificity" [27]. Yield of $\mathrm{CE}$ varies depending on the type of patient, and so forth, and it is lower when performed in patients with only abdominal pain [28] and in patients with abdominal pain and diarrhea [29]. In this way, the first consensus of the International Conference on Capsule Endoscopy (ICCE) concluded that $\mathrm{CE}$ is capable of identifying lesions of the mucosa of the small bowel overlooked with other imaging techniques and also defines CD suspicion group [30]. Further on, in order to improve the diagnosis yield of the CE, the ICCE proposed an algorithm including the main suspicion criteria for $\mathrm{CD}$ [31] (Figure 1). Colonoscopy with ileoscopy must always be performed prior to capsule endoscopy, considering it for $\mathrm{CD}$ diagnosis or exclusion if the patient presents suspicious symptoms (abdominal pain or persistent diarrhea) as well as extraintestinal manifestations, alteration of inflammatory markers, or abnormalities in other imaging tests [32]. In this sense, fecal calprotectin in small bowel CD can play an important role. Fecal calprotectin is a noninvasive marker of gastrointestinal inflammation with advocated diagnostic precision to differentiate Inflammatory Bowel Disease from nonIBD diagnoses. A recently published article has assessed the sensitivity and specificity of fecal calprotectin in suspected $\mathrm{CD}$ [33]. With a $50 \mathrm{mg} / \mathrm{kg}$ cut-off, $\mathrm{CD}$ in the small intestine and colon was diagnosed with $92 \%$ and $94 \%$ sensitivity, respectively, and the overall sensitivity and specificity were 95\% and 56\%. Therefore measurement of fecal calprotectin levels in patients with $\mathrm{CD}$ suspicion prior to referral for $\mathrm{CE}$ is a useful tool. In another study, nevertheless, the cut-off was higher and a fecal calprotectin $>200 \mu \mathrm{g} / \mathrm{g}$ was associated with higher CE yield (65\%) and confirmed CD in 50\% of cases; when fecal calprotectin $<100 \mu \mathrm{g} / \mathrm{g}$ (NPV 1.0), CE is not indicated [34]. In any case, more studies must be done because in another paper fecal biomarkers calprotectin and S100A12 have moderate specificity but low sensitivity [35].

The study by Tukey et al. [36] showed data of efficacy of $\mathrm{CE}$, with the overall sensitivity for the diagnosis of $\mathrm{CD}$ of $85 \%$, specificity of $73 \%$, PPV of $31 \%$, and negative predictive value of $97 \%$, but when the test characteristics were determined according to $\mathrm{CE}$ findings alone, those patients with $>3$ small bowel ulcers had a PPV of $50 \%$ for CD and, if assessed only in patients under 30 years, the sensitivity of CE is $100 \%$, specificity $78 \%$, and PPV $67 \%$ and in assessed selected group (ICCE's criteria about suspected CD) with a pretest likelihood of $50 \%$ CE led to a posttest probability of $85 \%$. $\mathrm{CE}$ has a number needed to test (NNT) of 3 to yield one additional diagnosis of $\mathrm{CD}$ over small bowel barium radiography and NNT of 7 over colonoscopy with ileoscopy [37]. In conclusion, in patients with suspected CD, CE has a high sensitivity and negative predictive value but low PPV, although selecting patients with symptoms in addition to other objective findings may enhance the PPV of CE.

\section{Special Situations}

3.1. Pediatric Crohn's Disease. Unlike in adults, suspected small bowel CD is the main indication for CE in the pediatric age group [38]. If clinical indications are age-stratified, in children of age 1.5-8 years (in whom $\mathrm{CD}$ is less prevalent), the most common indication for $\mathrm{CE}$ was obscure gastrointestinal bleeding [39]. In contrast, obscure gastrointestinal bleeding in older children (older than 10 years) accounted for only 13$24 \%$ of all indications and $40-86 \%$ of CD indications [40]. In any case, it is important to know that patients with childhoodonset $\mathrm{CD}$ exhibit a more active disease and require more immunosuppressive and biological therapy without relation to the disease location, suggesting an intrinsic more severe phenotype [41]. Consequently, a rapid diagnosis must be made in order to treat correctly these patients.

There are fewer studies evaluating the role of capsule endoscopy in children with suspected Crohn's disease. Guilhon de Araujo Sant'Anna et al. [42] studied 20 children with suspected Crohn's disease who had negative small bowel series and colonoscopy. In 10 of them CE demonstrated multiple erosions and ulcers consistent with $\mathrm{CD}$. We also used $\mathrm{CE}$ in 12 patients in the pediatric age [43]. The indication was a clinical suspicion of $\mathrm{CD}$ with a normal gastroscopy, colonoscopy, and small bowel follow-through series. Also ileoscopy was performed in $50 \%$ of the patients and no lesions were observed. In our study, CE identified lesions suggestive 
of $\mathrm{CD}$ in 7 of the 12 patients (58.3\%) with the majority of the lesions located in the ileum. Similar to adults all these findings result in a change in medical therapy for 75\%-92\% of known CD patients in various studies [44-46]. Also CE in pediatric age can lead to reclassification of IBD from UC/IC to $\mathrm{CD}$ and previously diagnosed $\mathrm{CD}$ patients may have a more significant burden of small bowel disease. In a recent study [47] CE was used in eighteen patients, 4 previously diagnosed with $\mathrm{CD}, 4$ with ulcerative or indeterminate colitis (UC/IC), and 10 "suspected" to have IBD. Following CE, 2 of $4(50 \%)$ UC/IC patients were reclassified as having small bowel CD. In the 4 subjects with known CD, 2 (50\%) had $\mathrm{CE}$ evidence of more proximal small bowel mucosal disease than previously recognized and, in the 10 subjects with "suspected" IBD, 8 (80\%) had small bowel ulcerations leading to a definitive diagnosis of $\mathrm{CD}$. These results also impacted medical decision-making in 13 of $18(72.2 \%)$, leading to a change in medical management in 14 of 18 (77.8\%). These data may help to integrate CE in evaluating IBD patients, lead to more targeted medical management changes, and improve outcomes.

3.2. Use of CE in Recurrence of CD. Recurrence of symptoms has been predicted by the early endoscopic appearance of lesions following ileocolonic resection for Crohn's disease. In order to avoid this recurrence and start treatment, $\mathrm{CE}$ has been adapted to detect postoperative recurrence of small bowel CD, but results are not conclusive. In one study CE was inferior to ileocolonoscopy detecting recurrence although lesions localized proximally were seen [48]. Unlike this, in the Pons et al. study [49] CE was more effective in the evaluation of recurrence after surgery for CD. Twenty-four patients with $\mathrm{CD}$ with ileocolonic anastomosis were prospectively included. Recurrences were visualized with colonoscopy in 6 patients and in 5 with CE but 10 additional recurrences were visualized only with CE. Moreover, proximal involvement was detected in 13 patients. Consequently, therapeutic management was modified in 16 patients.

It is important to conclude in this item that ileocolonoscopy should not be replaced to evaluate recurrence; however $\mathrm{CE}$ is a suitable alternative that can detect lesions more proximally also.

\section{Lesions Observed by $\mathrm{CE}$ and Evaluation Scores for CD}

The spectrum of the lesions observed by $\mathrm{CE}$ in patients with $\mathrm{CD}$ is varied and similar to the lesions observed by conventional endoscopy and it depends on the extent and severity of the CD. CE can usually detect mucosal fissure, linear ulcers, round ulcers, irregular ulcers, cobblestoning mucosa (composed of multiple longitudinal ulcers running parallel and hill-like elevations due to submucosal swelling), aphthous lesions, or strictured and ulcerated areas of mucosa scarring. Additionally it is able to observe bleeding lesions, polyps, and pseudopolyps suggestive of CD [50]. Other minor lesions, such as erythema, edema, loss of villi, denudated area, or aphthous ulcer, certainly not visualized by conventional radiological techniques, can be detected by
CE. The main problem is that all these lesions are not specific of $\mathrm{CD}$, and the differential diagnosis must be done mainly with lesions induced by NSAIDS, because some small-bowel lesions may be found in up to 75\% of NSAID users, even after 2 weeks' ingestion of such drugs [51,52] (Figures 2 and 3).

Some studies have been developed to define what type or number of lesions could be more specific of CD. Mow et al. [53] published their experience in the use of CE in patients with Inflammatory Bowel Disease. Nine patients out of 22 were given a diagnosis of definite CD (40\%) based on findings of linear erosions and multiple ulcerations by capsule study. Of these 9 patients, 5 had subsequent histological findings in agreement with capsule and clinical diagnosis of $\mathrm{CD}$. Outcome measures were classified as diagnostic when multiple ulcerations were present and suspicious when $\leq 3$ ulcerations were seen. Also, some evaluation systems for inflammatory diseases of the small bowel mucosa detected by capsule endoscopy have been designed. The Lewis Index [54] has been newly developed and scores 3 parameters: villous edema, ulceration, and stenosis (which are weighted based on extent and severity). A score lower than 135 is considered normal or clinically insignificant; scores between 135 and 790 are classified as mild and scores higher than 790 as moderate to severe. Nevertheless, the score cannot specify the etiology of the mucosal inflammatory changes observed. The Lewis score has been integrated into the last software from the PillCam (Given, Rapid Reader) making it more accessible. In one recently published study 56 patients underwent $\mathrm{CE}$ for suspected CD using the Lewis Score and the ICCE criteria, concluding that patients not fulfilling the ICCE criteria have lower Lewis score and therefore fewer are diagnosed with CD during follow-up [55]. In this study patients were divided into three groups, according to clinical presentation: Group 1 (28 patients), suspected CD not supported by the International Conference on Capsule Endoscopy (ICCE) criteria; Group 2 (19 patients), suspected CD based on two ICCE criteria; and Group 3 (9 patients), patients fulfilling three or more criteria. Inflammatory activity was assessed with Lewis score. CE detected significant inflammatory activity $(L S \geq 135)$ in 23 patients (41.1\%), 5 patients from Group 1 (17.8\%), 11 from Group 2 (57.9\%), and 7 from Group 3 (77.8\%) $(P<0.05)$. CD was diagnosed in 23 patients (41.1\%): 6 patients from Group 1 (21.4\%), 10 from Group 2 (52.6\%), and 7 from Group 3 (77.8\%) $(P<0.05)$. CD was diagnosed in $82.6 \%$ of patients with significant inflammatory activity on $\mathrm{CE}(\mathrm{LS} \geq 135)$, but in only $12.1 \%$ of those having a LS $<35(P<0.05)$. They conclude that Lewis score has a positive predictive value of $82,6 \%$, a negative predictive value of $87,9 \%$, a sensitivity of $82,6 \%$, and a specificity of $87.9 \%$. Korman et al. [56] proposed the capsule endoscopy structured terminology (CEST), which has been adopted as the terminology to be used for lesion description. Investigators used the CEST to create a description of a given finding (erythema, edema, nodularity, ulcer, and stenosis), number of findings, distribution pattern, longitudinal extent, shape, and size to create this scoring system. Gal et al. [57] also published a similar scoring system for CE titled capsule endoscopy Crohn's disease activity index (CECDAI) which includes evaluation of 3 parameters including inflammation, 

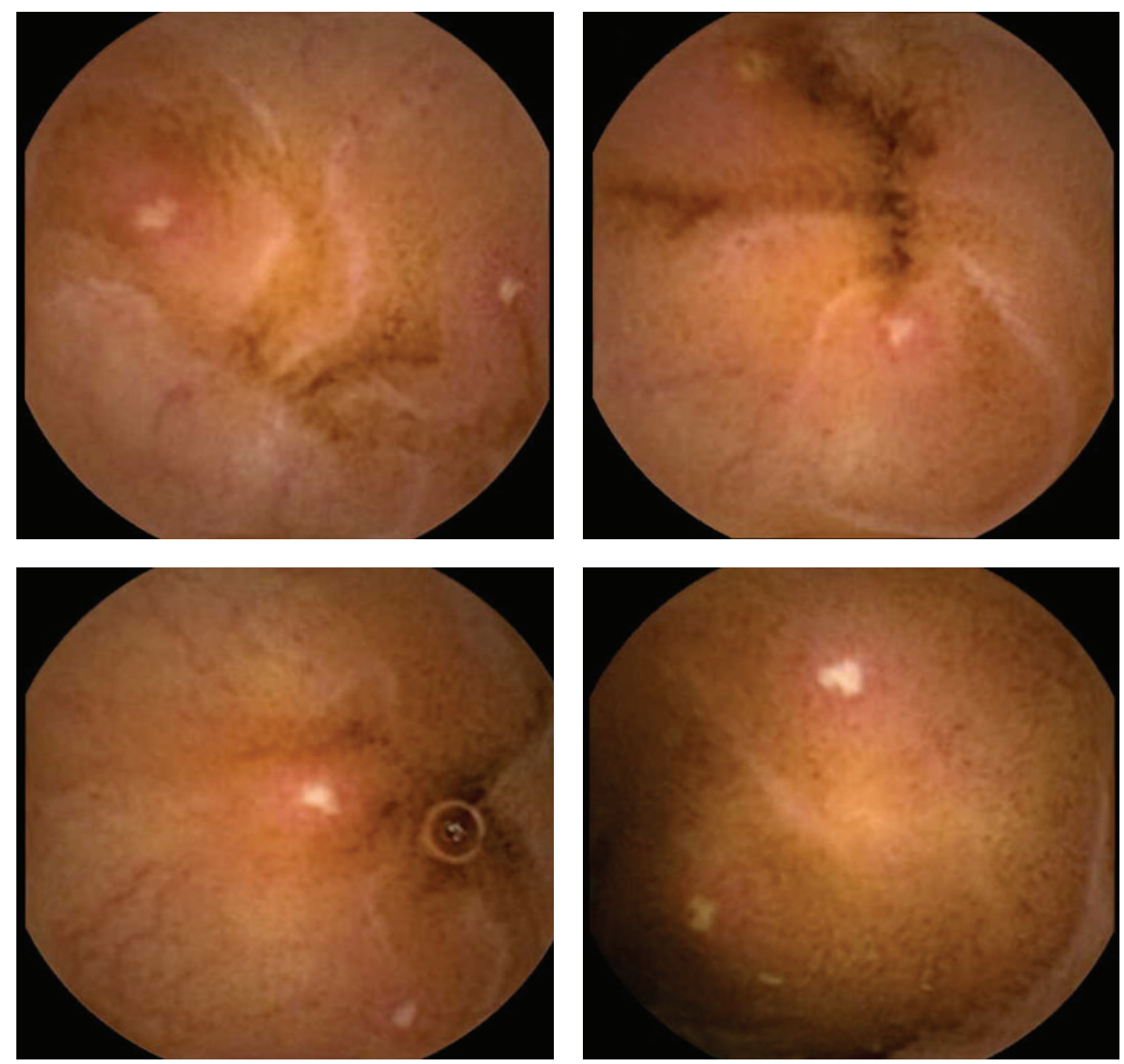

Figure 2: Aphthous lesions consistent with CD.

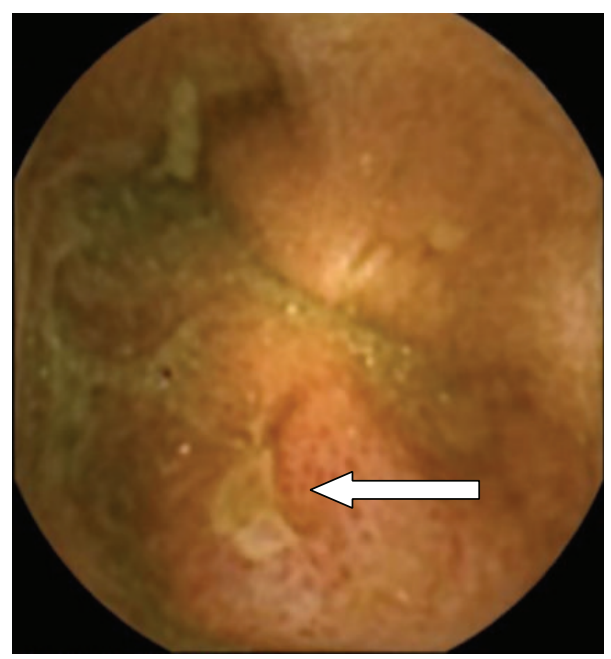

FIGURE 3: Ulcer in a user of NSAIDS.

extent of disease, and presence of stricture, all graded on a numeric scale with the small bowel divided into proximal and distal halves. The authors reported a kappa for the final score for each patient between different evaluations that was 0.87 .

Although these scoring systems can quantitatively describe the number and severity of mucosal abnormalities detected, they had no utility in distinguishing different diagnostic entities. In addition, no scoring system has been shown to have a relationship to the patient's clinical status or CDAI scores, so more studies must be done to improve or perform new score systems. 


\section{Complications}

Although CE is able to observe small bowel lesions better than other image techniques, CE retention is one important limitation. The ICCE consensus statement defined capsule retention as having a capsule endoscope remaining in the digestive tract for a minimum of two weeks [18]. The risk of retention is $1.5 \%$ when $\mathrm{CE}$ is performed in the setting of suspected CD, but $13 \%$ of cases have been reported in studies performed in the setting of previously known CD [64]. The choice of surgical, endoscopic, or medical management once capsule retention has been diagnosed depends on the cause of the retention, the indication for the exam, and previous treatment. A retained capsule is usually asymptomatic but may be associated with symptoms of partial or complete bowel obstruction or bowel perforation that has been reported [65]. In any case, there is not a consensus on the timing of intervention and how long one should wait in asymptomatic patients.

In an attempt to avoid this complication, a dissolving test capsule called "patency capsule" [66] was developed. It allows assessed patient with probable $\mathrm{CD}$ to safely undergo a CE, despite clinical and radiographic evidence of small bowel stenosis in $\mathrm{CD}$. The patency capsule is swallowed by the patient and the scan is 30 hours after ingestion. Thirtyeight percent of patency capsule is dissolved after $35 \mathrm{~h}$ and all are dissolved between 36 and $72 \mathrm{~h}$. Some cases of intestinal occlusion have been reported with the patency [67], so a new capsule with two-timer plus (Agile ${ }^{\mathscr{Q}}$ patency capsule) has recently been developed in order to minimize the risk of occlusion. A clinical trial [68] has demonstrated that it is a useful, noninvasive tool to identify which patients with suspected strictures could safely ingest the standard video capsule. In cases of an unsuccessful patency capsule procedure, the small bowel should be investigated by radiological imaging such as MRE or by enteroscopy. It is important to enhance that normal radiographic studies cannot entirely exclude the potential for small-bowel capsule retention and in case of a stricture suspected the Agile ${ }^{\odot}$ patency capsule should be considered [24].

\section{Conclusions}

Capsule endoscopy is a good method to evaluate the small bowel resulting in better outcomes of diagnosis, classification, therapeutic management, and prognosis of patients with CD. Nevertheless there remains much to be clarified: it is necessary to improve the specificity of the $\mathrm{CE}$ and to determine the place of the $\mathrm{CE}$ in the recurrence of $\mathrm{CD}$ and, for example, its role in monitoring drug response.

\section{Conflict of Interests}

The authors declare that there is no conflict of interests regarding the publication of this paper.

\section{References}

[1] J. Cosnes, C. Gower-Rousseau, P. Seksik, and A. Cortot, "Epidemiology and natural history of inflammatory bowel diseases," Gastroenterology, vol. 140, no. 6, pp. 1785-1794, 2011.

[2] J. A. Leighton, P. Legnani, and E. G. Seidman, "Role of capsule endoscopy in inflammatory bowel disease: where we are and where we are going," Inflammatory Bowel Diseases, vol. 13, no. 3, pp. 331-337, 2007.

[3] G. van Assche, A. Dignass, J. Panes et al., “The second European evidence-based consensus on the diagnosis and management of Crohn's disease: definitions and diagnosis," Journal of Crohn's and Colitis, vol. 4, no. 1, pp. 7-27, 2010.

[4] B. A. Lashner, "Clincial features, laboratory findings, and course of Crohn's disease," in Inflamatory Bowel Disease, J. B. Kirsner, Ed., pp. 305-314, Saunders, Philadelphia, Pa, USA, 5th edition, 2000.

[5] F. Molinié, C. Gower-Rousseau, T. Yzet et al., "Opposite evolution in incidence of Crohn's disease and ulcerative colitis in Northern France (1988-1999)," Gut, vol. 53, no. 6, pp. 843-848, 2004.

[6] M. Flamant, C. Trang, O. Maillard et al., "The prevalence and outcome of jejunal lesions visualized by small bowel capsule endoscopy in Crohn's disease," Inflammatory Bowel Diseases, vol. 19, no. 7, pp. 1390-1396, 2013.

[7] M. Lazarev, C. Huang, A. Bitton et al., "Relationship between proximal Crohn's disease location and disease behavior and surgery: a cross-sectional study of the IBD genetics consortium," The American Journal of Gastroenterology, vol. 108, no. 1, pp. 106-112, 2013.

[8] M. S. Gee and M. G. Harisinghani, "MRI in patients with inflammatory bowel disease," Journal of Magnetic Resonance Imaging, vol. 33, no. 3, pp. 527-534, 2011.

[9] S. K. Gölder, A. G. Schreyer, E. Endlicher et al., "Comparison of capsule endoscopy and magnetic resonance (MR) enteroclysis in suspected small bowel disease," International Journal of Colorectal Disease, vol. 21, no. 2, pp. 97-104, 2006.

[10] J. M. Herrerías, A. Caunedo, M. Rodríguez-Téllez, F. Pellicer, and J. M. Herrerías Jr., "Capsule endoscopy in patients with suspected Crohn's disease and negative endoscopy," Endoscopy, vol. 35, no. 7, pp. 564-568, 2003.

[11] Z. Fireman, E. Mahajna, E. Broide et al., "Diagnosing small bowel Crohn's disease with wireless capsule endoscopy," Gut, vol. 52, no. 3, pp. 390-392, 2003.

[12] J. Valle, M. Alcántara, M. J. Pérez-Grueso et al., "Clinical features of patients with negative results from traditional diagnostic work-up and Crohn's disease findings from capsule endoscopy," Journal of Clinical Gastroenterology, vol. 40, no. 8, pp. 692-696, 2006.

[13] C. M. Girelli, P. Porta, V. Malacrida, F. Barzaghi, and F. Rocca, "Clinical outcome of patients examined by capsule endoscopy for suspected small bowel Crohn's disease," Digestive and Liver Disease, vol. 39, no. 2, pp. 148-154, 2007.

[14] Z. Fireman, R. Eliakim, S. Adler, and E. Scapa, "Capsule endoscopy in real life: a four-centre experience of 160 consecutive patients in Israel," European Journal of Gastroenterology and Hepatology, vol. 16, no. 9, pp. 927-931, 2004.

[15] J. A. Leighton, I. M. Gralnek, S. A. Cohen et al., "Capsule endoscopy is superior to small-bowel follow-through and equivalent to ileocolonoscopy in suspected Crohn's disease," Clinical Gastroenterology and Hepatology, 2013. 
[16] R. Eliakim, A. Suissa, K. Yassin, D. Katz, and D. Fischer, "Wireless capsule video endoscopy compared to barium followthrough and computerised tomography in patients with suspected Crohn's disease-final report," Digestive and Liver Disease, vol. 36, no. 8, pp. 519-522, 2004.

[17] E. Dubcenco, K. N. Jeejeebhoy, R. Petroniene et al., "Capsule endoscopy findings in patients with established and suspected small-bowel Crohn's disease: correlation with radiologic, endoscopic, and histologic findings," Gastrointestinal Endoscopy, vol. 62, no. 4, pp. 538-544, 2005.

[18] A. Efthymiou, N. Viazis, J. Vlachogiannakos et al., "Wireless capsule endoscopy versus enteroclysis in the diagnosis of smallbowel Crohn's disease," European Journal of Gastroenterology and Hepatology, vol. 21, no. 8, pp. 866-871, 2009.

[19] R. Marmo, G. Rotondano, R. Piscopo et al., "Capsule endoscopy versus enteroclysis in the detection of small-bowel involvement in Crohn's disease: a prospective trial," Clinical Gastroenterology and Hepatology, vol. 3, no. 8, pp. 772-776, 2005.

[20] A. K. Chong, A. Taylor, A. Miller, O. Hennessy, W. Connell, and P. Desmond, "Capsule endoscopy vs. push enteroscopy and enteroclysis in suspected small-bowel Crohn's disease," Gastrointestinal Endoscopy, vol. 61, no. 2, pp. 255-261, 2005.

[21] M. D. Jensen, T. Nathan, S. R. Rafaelsen, and J. Kjeldsen, "Diagnostic accuracy of capsule endoscopy for small bowel Crohn's disease is superior to that of MR enterography or CT enterography," Clinical Gastroenterology and Hepatology, vol. 9, no. 2, pp. 124-129, 2011.

[22] S. L. Triester, J. A. Leighton, G. I. Leontiadis et al., "A metaanalysis of the yield of capsule endoscopy compared to other diagnostic modalities in patients with non-stricturing small bowel Crohn's disease," The American Journal of Gastroenterology, vol. 101, no. 5, pp. 954-964, 2006.

[23] P. M. Dionisio, S. R. Gurudu, J. A. Leighton et al., "Capsule endoscopy has a significantly higher diagnostic yield in patients with suspected and established small-bowel crohn's disease: a meta-analysis," The American Journal of Gastroenterology, vol. 105, no. 6, pp. 1240-1248, 2010.

[24] S. F. Pasha, J. A. Leighton, A. Das et al., "Double-balloon enteroscopy and capsule endoscopy have comparable diagnostic yield in small-bowel disease: a meta-analysis," Clinical Gastroenterology and Hepatology, vol. 6, no. 6, pp. 671-676, 2008.

[25] X. Chen, Z.-H. Ran, and J.-L. Tong, "A meta-analysis of the yield of capsule endoscopy compared to double-balloon enteroscopy in patients with small bowel diseases," World Journal of Gastroenterology, vol. 13, no. 32, pp. 4372-4378, 2007.

[26] B. M. Wiarda, M. Stolk, D. G. Heine et al., "Patient burden and patient preference: comparing magnetic resonance enteroclysis, capsule endoscopy and balloon-assisted enteroscopy," Journal of Gastroenterology and Hepatology, vol. 28, no. 3, pp. 464-471, 2013.

[27] A. Bourreille, A. Ignjatovic, L. Aabakken et al., "Role of small-bowel endoscopy in the management of patients with inflammatory bowel disease: an international OMED-ECCO consensus," Endoscopy, vol. 41, no. 7, pp. 618-637, 2009.

[28] C. Spada, G. A. Pirozzi, M. E. Riccioni, F. Iacopini, M. Marchese, and G. Costamagna, "Capsule endoscopy in patients with chronic abdominal pain," Digestive and Liver Disease, vol. 38, no. 9, pp. 696-698, 2006.

[29] L. C. Fry, E. J. Carey, A. D. Shiff et al., "The yield of capsule endoscopy in patients with abdominal pain or diarrhea," Endoscopy, vol. 38, no. 5, pp. 498-502, 2006.
[30] A. Kornbluth, J. F. Colombel, J. A. Leighton, and E. Loftus, "ICCE consensus for inflammatory bowel disease," Endoscopy, vol. 37, no. 10, pp. 1051-1054, 2005.

[31] K. Mergener, T. Ponchon, I. Gralnek et al., "Literature review and recommendations for clinical application of small-bowel capsule endoscopy, based on a panel discussion by international experts," Endoscopy, vol. 39, no. 10, pp. 895-909, 2007.

[32] B. S. Lewis, "Expanding role of capsule endoscopy in inflammatory bowel disease," World Journal of Gastroenterology, vol. 14, no. 26, pp. 4137-4141, 2008.

[33] M. D. Jensen, J. Kjeldsen, and T. Nathan, "Fecal calprotectin is equally sensitive in Crohn's disease affecting the small bowel and colon," Scandinavian Journal of Gastroenterology, vol. 46, no. 6, pp. 694-700, 2011.

[34] A. Koulaouzidis, S. Douglas, M. A. Rogers, I. D. Arnott, and J. N. Plevris, "Fecal calprotectin: a selection tool for small bowel capsule endoscopy in suspected IBD with prior negative bidirectional endoscopy," Scandinavian Journal of Gastroenterology, vol. 46, no. 5, pp. 561-566, 2011.

[35] T. Sipponen, J. Haapamäki, E. Savilahti et al., "Fecal calprotectin and S100A12 have low utility in prediction of small bowel Crohn's disease detected by wireless capsule endoscopy", Scandinavian Journal of Gastroenterology, vol. 47, no. 7, pp. 778-784, 2012.

[36] M. Tukey, D. Pleskow, P. Legnani, A. S. Cheifetz, and A. C. Moss, "The utility of capsule endoscopy in patients with suspected Crohn's disease," The American Journal of Gastroenterology, vol. 104, no. 11, pp. 2734-2739, 2009.

[37] S. K. Gölder, A. G. Schreyer, E. Endlicher et al., "Comparison of capsule endoscopy and magnetic resonance (MR) enteroclysis in suspected small bowel disease," International Journal of Colorectal Disease, vol. 21, no. 2, pp. 97-104, 2006.

[38] S. A. Cohen, H. Ephrath, J. D. Lewis et al., "Pediatric capsule endoscopy: review of the small bowel and patency capsules," Journal of Pediatric Gastroenterology and Nutrition, vol. 54, no. 3, pp. 409-413, 2012.

[39] A. Fritscher-Ravens, P. Scherbakov, P. Bufler et al., "The feasibility of wireless capsule endoscopy in detecting small intestinal pathology in children under the age of 8 years: a multicentre European study," Gut, vol. 58, no. 11, pp. 1467-1472, 2009.

[40] S. A. Cohen and A. I. Klevens, "Use of capsule endoscopy in diagnosis and management of pediatric patients, based on meta-analysis," Clinical Gastroenterology and Hepatology, vol. 9, no. 6, pp. 490-496, 2011.

[41] B. Pigneur, P. Seksik, S. Viola et al., "Natural history of Crohn's disease: comparison between childhood- and adultonset disease," Inflammatory Bowel Diseases, vol. 16, no. 6, pp. 953-961, 2010.

[42] A. M. Guilhon de Araujo Sant'Anna, J. Dubois, M.-C. Miron, and E. G. Seidman, "Wireless capsule endoscopy for obscure small-bowel disorders: final results of the first pediatric controlled trial," Clinical Gastroenterology and Hepatology, vol. 3, no. 3, pp. 264-270, 2005.

[43] F. Argüelles-Arias, A. Caunedo, J. Romero et al., "The value of capsule endoscopy in pediatric patients with a suspicion of Crohn's disease," Endoscopy, vol. 36, no. 10, pp. 869-873, 2004.

[44] S. A. Cohen, I. M. Gralnek, H. Ephrath et al., "Capsule endoscopy may reclassify pediatric inflammatory bowel disease: a historical analysis," Journal of Pediatric Gastroenterology and Nutrition, vol. 47, no. 1, pp. 31-36, 2008.

[45] G. L. de’ Angelis, F. Fornaroli, N. de Angelis, B. Magiteri, and B. Bizzarri, "Wireless capsule endoscopy for pediatric small-bowel 
diseases," The American Journal of Gastroenterology, vol. 102, no. 8, pp. 1749-1757, 2007.

[46] L. Moy and J. Levine, "Wireless capsule endoscopy in the pediatric age group: experience and complications," Journal of Pediatric Gastroenterology and Nutrition, vol. 44, no. 4, pp. 516520, 2007.

[47] I. M. Gralnek, S. A. Cohen, H. Ephrath et al., "Small bowel capsule endoscopy impacts diagnosis and management of pediatric inflammatory bowel disease: a prospective study," Digestive Diseases and Sciences, vol. 57, no. 2, pp. 465-471, 2012.

[48] A. Bourreille, M. Jarry, P. N. D'Halluin et al., "Wireless capsule endoscopy versus ileocolonoscopy for the diagnosis of postoperative recurrence of Crohn's disease: a prospective study, Gut, vol. 55, no. 7, pp. 978-983, 2006.

[49] B. V. Pons, P. Nos, G. Bastida et al., "Evaluation of postsurgical recurrence in Crohn's disease: a new indication for capsule endoscopy?" Gastrointestinal Endoscopy, vol. 66, no. 3, pp. 533540, 2007.

[50] M. Salgado and M. Masacarenhas-Saraiva, "Inflammatory bowel disease of small bowel," in Atlas of Capsule Endoscopy 2, J. M. Herrerías and M. Masacarenhas-Saraiva, Eds., pp. 211-223, 2012.

[51] D. Y. Graham, A. R. Opekun, F. F. Willingham, and W. A. Qureshi, "Visible small-intestinal mucosal injury in chronic NSAID users," Clinical Gastroenterology and Hepatology, vol. 3, no. 1, pp. 55-59, 2005.

[52] L. Maiden, B. Thjodleifsson, A. Seigal et al., "Long-term effects of nonsteroidal anti-inflammatory drugs and cyclooxygenase2 selective agents on the small bowel: a cross-sectional capsule enteroscopy study," Clinical Gastroenterology and Hepatology, vol. 5, no. 9, pp. 1040-1045, 2007.

[53] W. S. Mow, S. K. Lo, S. R. Targan et al., "Initial experience with wireless capsule enteroscopy in the diagnosis and management of inflammatory bowel disease," Clinical Gastroenterology and Hepatology, vol. 2, no. 1, pp. 31-40, 2004.

[54] I. M. Gralnek, R. Defranchis, E. Seidman, J. A. Leighton, P. Legnani, and B. S. Lewis, "Development of a capsule endoscopy scoring index for small bowel mucosal inflammatory change," Alimentary Pharmacology and Therapeutics, vol. 27, no. 2, pp. 146-154, 2008.

[55] B. Rosa, M. J. Moreira, A. Rebelo, and J. Cotter, "Lewis Score: a useful clinical tool for patients with suspected Crohn's Disease submitted to capsule endoscopy," Journal of Crohn's and Colitis, vol. 6, no. 6, pp. 692-697, 2012.

[56] L. Y. Korman, M. Delvaux, G. Gay et al., "Capsule endoscopy structured terminology (CEST): proposal of a standardized and structured terminology for reporting capsule endoscopy procedures," Endoscopy, vol. 37, no. 10, pp. 951-959, 2005.

[57] E. Gal, A. Geller, G. Fraser, Z. Levi, and Y. Niv, "Assessment and validation of the new capsule endoscopy Crohn's disease activity index (CECDAI)," Digestive Diseases and Sciences, vol. 53, no. 7, pp. 1933-1937, 2008.

[58] G. A. Doherty, A. C. Moss, and A. S. Cheifetz, "Capsule endoscopy for small-bowel evaluation in Crohn's disease," Gastrointestinal Endoscopy, vol. 74, no. 1, pp. 167-175, 2011.

[59] W. A. Voderholzer, J. Beinhoelzl, P. Rogalla et al., "Small bowel involvement in Crohn's disease: a prospective comparison of wireless capsule endoscopy and computed tomography enteroclysis," Gut, vol. 54, no. 3, pp. 369-373, 2005.

[60] A. K. Hara, J. A. Leighton, R. I. Heigh et al., "Crohn disease of the small bowel: preliminary comparison among CT enterography, capsule endoscopy, small-bowel follow-through, and ileoscopy," Radiology, vol. 238, no. 1, pp. 128-134, 2006.

[61] E. Casciani, G. Masselli, G. di Nardo et al., "MR enterography versus capsule endoscopy in paediatric patients with suspected Crohn's disease," European Radiology, vol. 21, no. 4, pp. 823-831, 2011.

[62] C. Tillack, J. Seiderer, S. Brand et al., "Correlation of magnetic resonance enterocylsis (MRE) and wireless capsule endoscopy (CE) in the diagnosis os small bowel lesions in Crohn's disease," Inflammatory Bowel Diseases, vol. 14, no. 9, pp. 1219-1228, 2008.

[63] J. G. Albert, F. Martiny, A. Krummenerl et al., "Diagnosis of small bowel Crohn's disease: a prospective comparison of capsule endoscopy with magnetic resonance imaging and fluoroscopic enteroclysis," Gut, vol. 54, no. 12, pp. 1721-1727, 2005.

[64] A. S. Cheifetz, A. A. Kornbluth, P. Legnani et al., "The risk of retention of the capsule endoscope in patients with known or suspected Crohn's disease," The American Journal of Gastroenterology, vol. 101, no. 10, pp. 2218-2222, 2006.

[65] J. S. Palmer, K. Marenah, F. El Madani, K. Jain, and S. Gupta, "Small bowel perforation following capsule endoscopy: a case report," Annals of the Royal College of Surgeons of England, vol. 93, no. 6, pp. e69-e70, 2011.

[66] Á. Caunedo-Álvarez, J. Romero-Vazquez, and J. M. HerreriasGutierrez, "Patency and agile capsules," World Journal of Gastroenterology, vol. 14, no. 34, pp. 5269-5273, 2008.

[67] G. Gay, M. Delvaux, V. Laurent et al., “Temporary intestinal occlusion induced by a "patency capsule" in a patient with Crohn's disease," Endoscopy, vol. 37, no. 2, pp. 174-177, 2005.

[68] J. M. Herrerias, J. A. Leighton, G. Costamagna et al., "Agile patency system eliminates risk of capsule retention in patients with known intestinal strictures who undergo capsule endoscopy," Gastrointestinal Endoscopy, vol. 67, no. 6, pp. 902-909, 2008. 


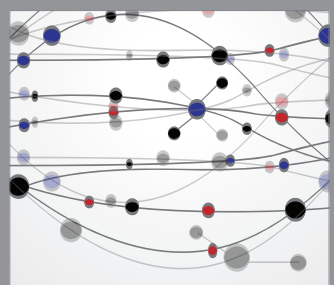

The Scientific World Journal
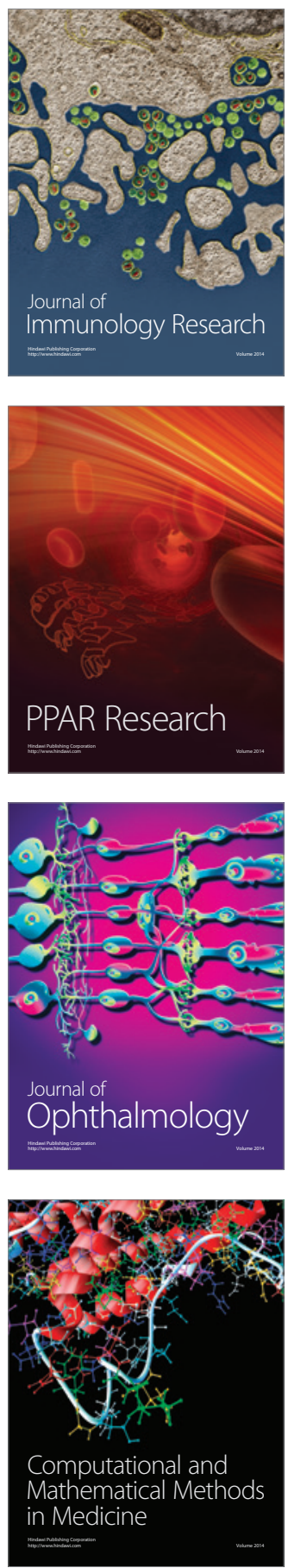

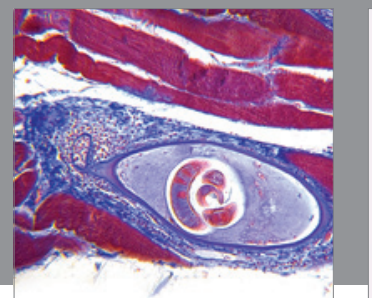

Gastroenterology

Research and Practice
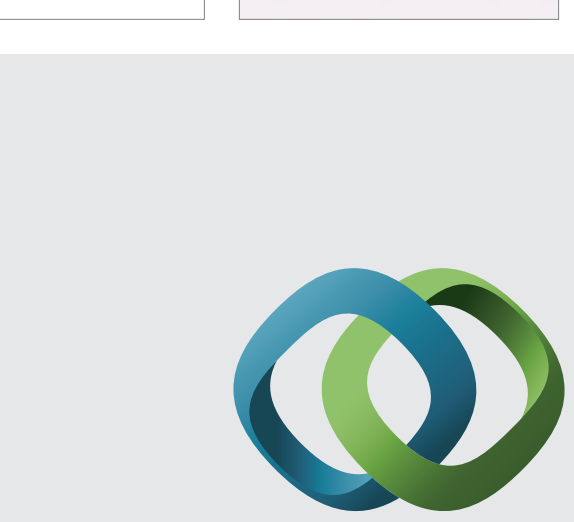

\section{Hindawi}

Submit your manuscripts at

http://www.hindawi.com
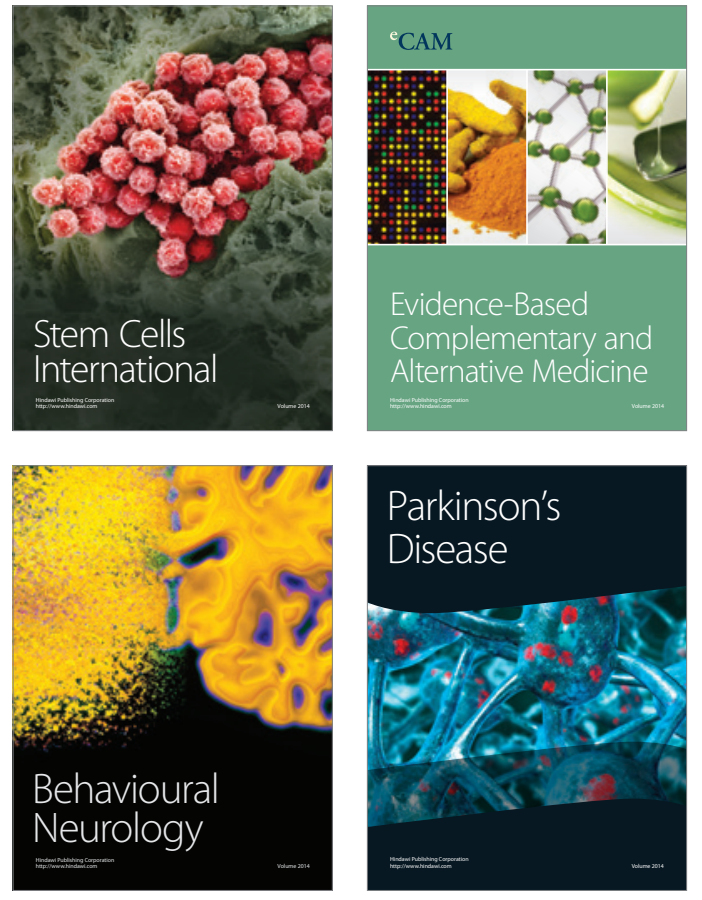
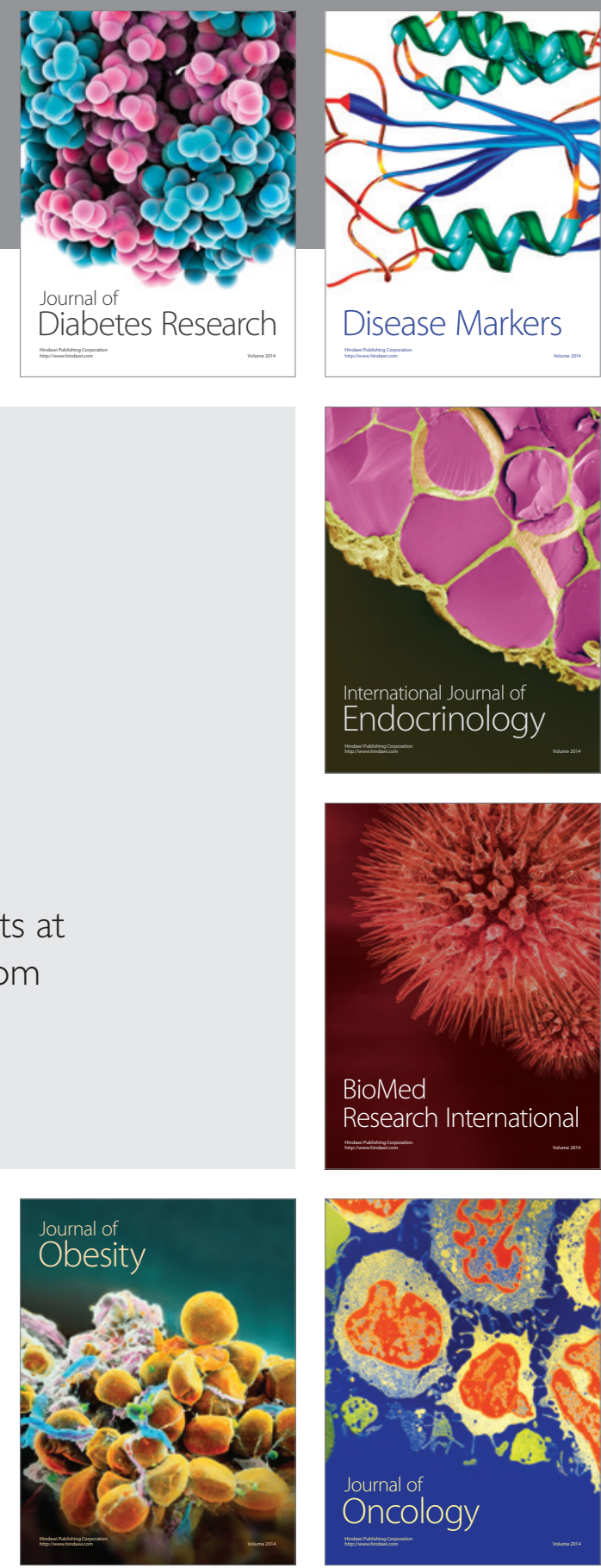

Disease Markers
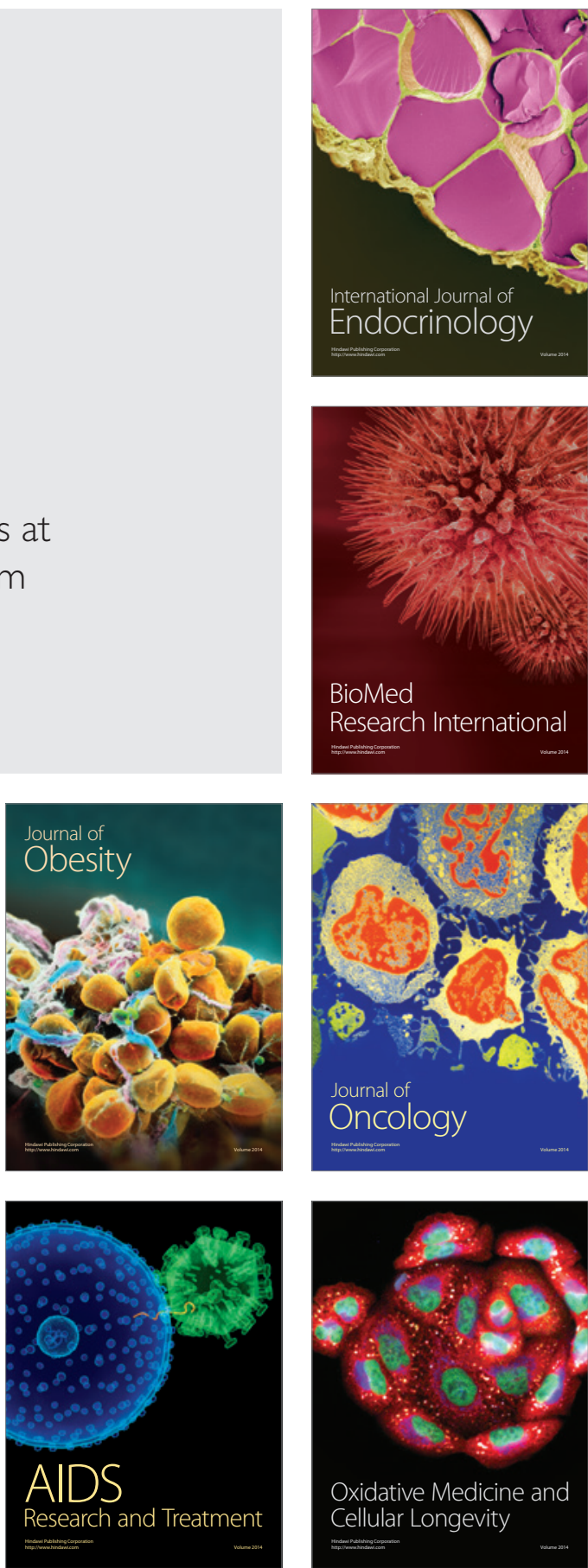